\title{
How long do fillings last?
}

Chadwick B, Dummer P, Dunstan F, et al. The Longevity of Dental Restorations. A Systematic Review. National Health System Centre for Reviews and Dissemination Report 19. York: University of York, 2001

\section{Question: In patients requiring dental restoration which filling material lasts longest?}

Objective To assess whether there were variations in the longevity and the cost of different routine dental restorations. To establish the factors that influence longevity of routine dental restorations focusing on various patient, material and operator factors, as well as choice of outcome criteria to describe treatment success and failure.

Data sources Sixteen electronic databases and Internet sources such as Derweb and American College of Physicians Journal Club were used. Hand searches were made of 36 dental journals (limited to English-language publications) and abstracts and proceedings from various societies of dental research.

Study selection Studies were excluded if they were not of human subjects, if they were laboratory-based, toxicity studies only, or if they were not relevant eg, not intracoronal. Studies reporting only restoration wear or degradation were excluded.
Findings The overall quality of reporting was mediocre. A number of recurrent problems in the presentation of results were identified which should be borne in mind in future reporting of this type of study. A summary is given in Table 1 .

Conclusions Specific recommendations were made for the different restorative materials but the general conclusion was that to obtain more reliable cost and relative-outcome measurements, a long-term prospective cohort study is needed across different dental settings.

Evidence-Based Dentistry (2002) 3, 96-99. doi:10.1038/ sj.ebd. 6400146

Address for correspondence: B. Chadwick, Dental School, University of Wales College of Medicine, Health Park, Cardiff, Wales.

Table 1 Summary of findings

\begin{tabular}{|c|c|c|}
\hline Subject of study & $\begin{array}{l}\text { Studies } \\
\text { (n) }\end{array}$ & Findings \\
\hline Amalgam & 62 & $\begin{array}{l}\text { At } 10 \text { years, }<10 \% \text { of restorations had been replaced (but no data for } 52 \% \text { of restorations). Preselection } \\
\text { of patients may also have favourable effect. Operator skill has an effect but there appeared to be no } \\
\text { greater reduction in survival of larger amalgam restorations than smaller ones. Some evidence to suggest } \\
\text { that dispersed-phase, high-copper-alloy amalgams have greater survival than other amalgams, but no } \\
\text { difference between polished and unpolished amalgams at } 36 \text { months }\end{array}$ \\
\hline Composite without dentine bonding & 48 & $\begin{array}{l}\text { Good short-term survival ( } 2-3 \text { years). The few studies with } \geqslant 5 \text { years follow-up showed signs of failure, } \\
\text { particularly multicentre studies. Survival influenced by material type }\end{array}$ \\
\hline Composite with dentine bonding & 25 & $\begin{array}{l}\text { Dentine bonding materials are often tested in cervical cavities, in which the failure of these materials is } \\
\text { rapid (beginning within } 1 \text { year). Materials that use some form of acidic primer demonstrate improved } \\
\text { survival. Enamel etching (with/without enamel bevel) and mechanical retention improve retention of } \\
\text { restorations. Use of all dentine bonding systems reduced patient pain after placement }\end{array}$ \\
\hline Amalgam versus composite & 26 & $\begin{array}{l}\text { In unpaired design amalgam was superior: in paired design differences in favour of amalgam were less but } \\
\text { still statistically significant }\end{array}$ \\
\hline Other materials & 45 & $\begin{array}{l}\text { Atraumatic restorative treatment (ART) has reasonable retention rates but other factors yet to be } \\
\text { assessed. Cermet cement and Glass-ionomer Cement }(\mathrm{GIC}) \text { used in the composite/GIC sandwich } \\
\text { technique had low survival rates. Gallium also had high failure rates and cannot be recommended }\end{array}$ \\
\hline Inlays & 27 & $\begin{array}{l}\text { Overall no important difference between porcelain and composite inlays. One small study compared } \\
\text { porcelain inlays with amalgam and found identical survival at } 2 \text { years }\end{array}$ \\
\hline Cost-effectiveness & 30 & $\begin{array}{l}\text { All studies poor quality so data provided by dentists on the time taken to carry out restorations was used } \\
\text { to make cost-effectiveness comparison of filling materials. Because amalgam is cheaper and has better } \\
\text { survival it dominates composite and inlays across all time periods considered }\end{array}$ \\
\hline
\end{tabular}

\section{Commentary}

In spite of the question being of great relevance to practitioners, patients and society the evidence base addressing the costs and longevity of dental restorations was until recently fairly limited. This changed when an expert team located at the University of Wales made a sys- tematic review of the topic. The review was initiated by the National Health System (NHS) Centre for Reviews and Dissemination located in York, UK.

The findings have been published in a number of formats: the report itself, consisting of 340 pages of text and data was published in 2001; and there are two summary papers, ${ }^{1,2}$ one of which is available on the Internet (www.york.ac.uk/inst/crd/ehc52.pdf).

A further published paper highlights the problems the team encountered during the preparation of the review, which should raise concern both in the dental research community and amongst research funding agencies. ${ }^{3}$ 
The review supersedes previous estimates of restoration-longevity based on age of replaced restorations, ${ }^{4}$ surveys of dentist opinions, ${ }^{5}$ approximately 20 longevity studies such as that by Hunter $(1985)^{6}$ showing an extensive heterogeneity of clinical variables, and a diminutive number of (non-systematic) reviews such as that of Mjör et al. (1990). ${ }^{7}$ As with other recent dental reviews, other groups were concurrently conducting systematic reviews of the same issue elsewhere within the UK, ${ }^{8}$ Germany ${ }^{9}$ and Switzerland ${ }^{10}$, and internationally by the FDI World Dental Federation. ${ }^{11}$ None of these reviews, however, matched the comprehensiveness of this vast NHS report. What they do all agree is that there is a long way to go before the methodological quality of dental restoration studies improves to a sufficient extent for valid meta-analyses. The review by Downer et al (1999). ${ }^{8}$ illustrates the dilemma: the authors identified only six longitudinal studies that were considered methodologically adequate from 124 research reports on clinical longevity of class I and class II restorations in permanent teeth.

The figure 1 gives some indication of the problems that the reviewers encountered when analysing the potentially relevant study papers. Several issues need to be considered when assessing the validity of this systematic review:

\section{How complete was the search?}

One of the most impressive features of this review is the multiple searches of various resources to identify relevant studies. The detailed search strategies employed in Medline and Embase are included in a separate appendix. Although no other reports on this topic include such comprehensive searches several clinical studies published in German were not identified eg Jahn et $a l^{12}$. Moreover, many studies are presented at the annual meetings of the American and International Associations for Dental Research (AADR/ IADR), but only one such abstract was included in the review and none were

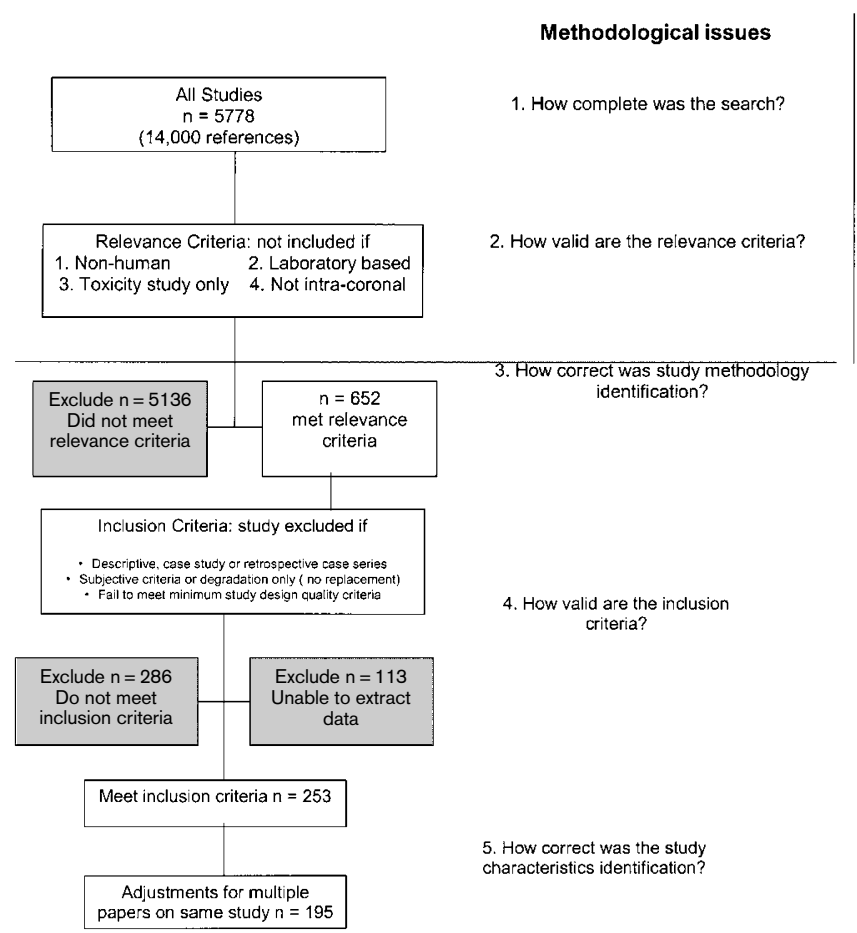

Figure 1 Flow Chart showing included studies and methodological issues

listed on the list of excluded studies. This indicates that either sooner or later all the AADR/IADR abstracts have resulted in journal articles, or that the review missed a number of these reports.

\section{How valid are the relevance criteria?} Nearly $90 \%$ of the reports excluded by initial eligibility criteria were discarded because they were in vitro studies. Many have questioned the clinical relevance of laboratory data, as it has been shown repeatedly that the correlation between in vitro data and clinical performance is poor $^{13}$.

3. How correct was the identification of study methodology?

Because of the number of studies (5788), the authors selected papers according to titles and abstracts. This introduces the possibility of selection bias by not reading the full paper. It is difficult to estimate the magnitude of this bias, but it is probably minor for high-quality studies if written in English and published in reputable dental journals.
4. How valid are the inclusion criteria? Systematic reviews occasionally end up with disparate conclusions even if they focus on exactly the same topic, eg, passive smoking, splint treatment for temporomandibular dysfunction, third molar extractions. The main reason for these differences is the inclusion and exclusion criteria. Usually, the criteria focus on study methodology, type of intervention, selection of treatment outcomes, population demographics and clinical settings. When appraising any systematic review it is important to consider whether the description of these details is adequate. Secondly, one must question whether the selection criteria seem valid and reasonable.

The first selection criteria reduced the number of relevant studies from 5788 to 652. The authors then allocated the studies into nine different study-design categories and assessed whether the reported outcome measures could be considered strong or weak. In vitro studies, descriptive studies, reports of expert committees, case studies and retrospective case series were excluded. Moreover, studies that focused only on 
degradation aspects, eg, wear or marginal degradation, with no report of replacements, were also discarded. Studies were also excluded if the authors had failed to describe clinical criteria that were applied when restoration replacements were reported. If other methodological problems were encountered, such as if fewer than $90 \%$ of participants were followed up with no valid reason for patient dropouts, or if the follow-up numbers were unclear, the paper was excluded.

At this stage there were 366 studies identified, consisting of prospective case series, retrospective studies with concurrent controls, prospective studies with historical or concurrent controls, other controlled trials and randomised controlled trials reporting some measure of restoration replacement incidence according to a set of specified criteria such as the United States Public Health Services or California Dental Association Criteria evaluation criteria.

Following a more detailed appraisal the authors experienced great problems with the poor reporting in the studies. In fact, they found it impossible to extract relevant data from the text in 113 papers, so these studies were also excluded from the review. This critical scrutiny of the study design reduced the number of relevant studies from 366 to 253. In accordance with conventional systematic review all the excluded studies are listed in the report with reasons for exclusion. The reader is thereby able to verify whether a selection bias of potentially relevant studies has occurred or not, ensuring the principle of transparency in systematic reviewing.

After correcting for multiple paper reports from single trials the final set of studies that were reviewed and formed the basis for the authors' conclusions was 195 longitudinal trials.

\section{How correct was the identification of} the study characteristics?

The inadequacy of study description caused major difficulties for the reviewers trying to address the validity and quality of the studies as well as difficulty in extracting data. This is a common finding in reviews on this topic. $^{8-11}$ For example, in the Swiss systematic review of direct posterior resin-based composite restorations none of 45 articles, even when of high methodological strength, were of satisfactory quality in their descriptions of methods and materials. ${ }^{10}$ This review enables the reader to assess whether all relevant aspects of each study have been addressed: the Tables presenting extracted details span more than 200 pages. The quality of study-reporting is unfortunately not only limited to the field of restorative dentistry. This issue needs to be addressed: even excellent clinical trials reported inadequately will erode their scientific impact. It is surprising that CONSORT ${ }^{14}$ and other guidelines are not often followed in dental journals.

The report includes an economic evaluation, which uses a complex model to derive a cost per tooth-life-year in order to develop cost profiles of each restoration type. The main conclusion is that amalgam is by far the most costeffective material. Unfortunately, the limited number of studies $(n=30)$, heterogeneity and low methodological quality cast doubt on the validity and general applicability of the conclusions of this economic evaluation. This is reflected by the authors' statement that there is a need to carry out a prospective cohort study across different dental settings to accurately document the inputs and costs associated with dental restorations over a relatively long period of time.

\section{Results}

Summaries of longevity data are given for amalgam, composite resin, glass ionomer cement, composite and ceramic inlay materials, Cermet, compomer and dentine bonding agents used in class V cavities (see Table 1). Few trials addressed gold inlays $(\mathrm{n}=1)$, silicate cement $(\mathrm{n}=3)$, and gallium $(\mathrm{n}=1)$. Survival data for deciduous and permanent teeth at $1,2,3,5$ and 10 years are presented in a boxplot format if available, which facilitates comparison between the different materials. Cumulative survival estimates are also presented. The data presented in figure 2 shows that glass ionomer cements has the poorest, whereas amalgam has the best, clinical performance in both deciduous teeth and in permanent teeth.

Only one third $(n=60)$, of the 195 studies compared different materials: the majority $(n=135)$ compared different products within the same material group or were designed to address the effects of certain handling procedures on survival. The longevity estimate for amalgam is reported to be shorter in the studies where it was compared with alternative materials than in studies where no such comparisons were made. The reason for this not immediately obvious, but the most likely reason is that it is an effect of publication bias.

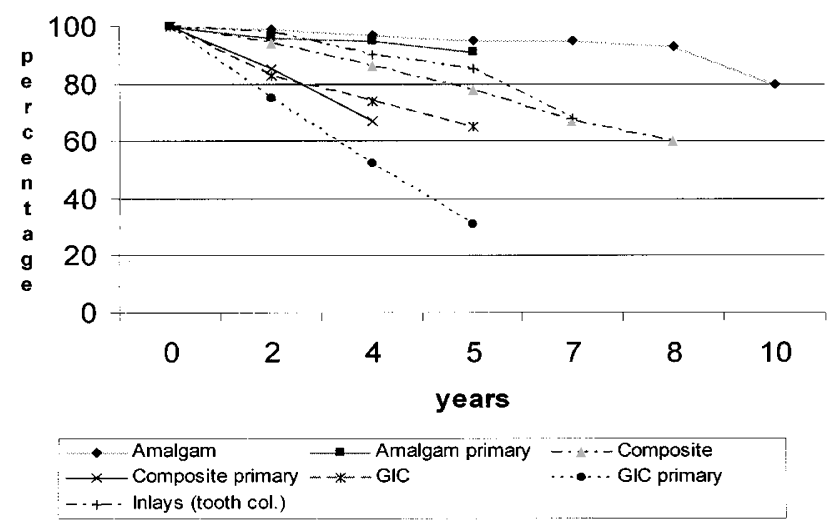

Figure 2 Estimates of longevity of dental restorations 
Lack of detail in the studies (Table 2) restricted attempts to relate clinical performance to various demographic and operator variables (effect modifiers), as did possible associations with study methodology quality.

Table 2 Examples of details not provided in studies

Use of percentage instead of actual numbers Confusing use of outcome criteria scales such as the USPHS scale

Lack of patient baseline information

Tooth and cavity type

Clinicians' level of skill

Criteria to identify failure

Evaluator characteristics

Payment system

Sponsorship

USPHS, United States Public Health Services

\section{Conclusions}

This systematic review attempts to answer a rather basic question about the longevity of dental restorations, with the perhaps disappointing conclusion that the answer is none too clear. Data and conclusions are clearly presented for each material together with suggestions for future research. Three suggestions for future research were repeatedly mentioned for all the materials:

- rigorous study design and more empiric measures of the effect modifiers;
- develop multicentre, multioperator studies with stratification of tooth type, cavity type and other effect modifiers for assessment periods of greater than 10 years; and

- more research must be carried out in general practice settings.

It is easy to agree with these conclusions. Although the cost and logistics of a 10-year prospective, controlled, longitudinal study is probably beyond the reach of any single dental teaching institution, similar problems have been overcome in medicine and mega-trials conducted and methodological issues addressed. Is the political will and academic-professional cooperation there to make it happen in this case?

1. Chadwick B, Dummer P, Dunstan F, et al. Dental restoration: what type of filling? Effective Health Care 1999; 5:2.

2. Chadwick BL, Dummer PM, Dunstan FD, et al. What type of filling? Best practice in dental restorations. Qual Health Care 1999; 8:202-207.

3. Chadwick B, Treasure E, Dummer $P$, et al. Challenges with studies investigating longevity of dental restorations - a critique of a systematic review. J Dent 2001; 29:155-161.

4. Mjör IA. Placement and replacement of restorations. Oper Dent 1981; 6:49-54.

5. Maryniuk GA, Kaplan SH. Longevity of restorations: survey results of dentists' estimates and attitudes. J Am Dental Assoc 1986; 112:39-45.

6. Hunter B. Survival of dental restorations in young patients. Community Dent Oral Epidemiol 1985; 13:285-287.
7. Mjör IA, Jokstad A, Qvist V. Longevity of posterior restorations. Int Dental J 1990; 40:11-17.

8. Downer MC, Azli NA, Bedi R, Moles DR, Setchell DJ. How long do routine dental restorations last? A systematic review. $\mathrm{Br}$ Dental J 1999; 187:432-439.

9. Hickel R, Manhart J, Garcia-Godoy F. Clinical results and new developments of direct posterior restorations. Am J Dent 2000; 13 (suppl):41D-54D.

10. Schmidlin P, Hofer E, Lutz F. Evaluation of published clinical studies for reproducibility, comparability and adherence to evidencebased methods. Am J Dent 2002; 15:2630.

11. Jokstad A, Bayne S, Blunck U, Tyas $M$, Wilson NHF. Quality of dental restorations. FDI scientific commission project 2-95. Int Dental J 2001; 53:117-158.

12. Wilson NHF. The evaluation of materials: relationship between laboratory investigations and clinical studies. Oper Dent 1990; 15:149-155

13. Jahn KR, Hansche $C$, Zuhrt R. Klinisch kontrolliertes experiment zur sekundärkarieshäufigkeit um amalgam bsw gussfüllungen. Stomatol DDR 1989; 39(4): 225-229.

14. Moher D, Schulz KF, Altman DG, CONSORT Group. The CONSORT statement: revised recommendations for improving the quality of reports of parallelgroup randomised trials. JAMA 2001; 285:1987-1991.

Asbjørn Jokstad
Professor,
Institute of Clinical Dentistry,
University of Oslo,
Oslo,
Norway

